\title{
Anticancer effect of curcumin inhibits cell growth through miR-21/PTEN/Akt pathway in breast cancer cell
}

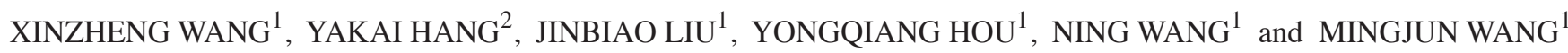 \\ ${ }^{1}$ Department III of General Surgery, The First Affiliated Hospital of Henan University of Science and Technology, \\ Luoyang, Henan 471000; ${ }^{2}$ Department of General Surgery, Peking Union Medical College Hospital, \\ Chinese Academy of Medical Sciences and Peking Union Medical College, Beijing 100730, P.R. China
}

Received March 28, 2015; Accepted April 22, 2016

DOI: $10.3892 / \mathrm{ol} .2017 .6053$

\begin{abstract}
Curcumin is a polyphenol extracted from turmeric, which that belongs to the Zingiberaceae family. Curcumin has numerous effects, including anti-inflammatory, antitumor, anti-oxidative and antimicrobial effects. However, the effects of curcumin on human breast cancer cells remain largely unknown. The aim of the present study was to investigate the anticancer effects and the mechanisms by which curcumin affects breast cancer cells. The anticancer effect of curcumin on cell viability and cytotoxicity on human breast cancer MCF-7 cells was analyzed using 3-(4,5-dimethyl-2-thiazolyl)-2, 5-diphenyl-2H-tetrazolium bromide and lactate dehydrogenase assays, respectively. Cell apoptosis of MCF-7 cells was detected using flow cytometry, 4',6-diamidino-2-phenylindolestaining assay and caspase-3/9 activity kits. Reverse transcription-quantitative polymerase chain reaction was used to analyze microRNA-21 (miR-21) expression in MCF-7 cells. The protein expression of phosphatase and tensin homolog (PTEN) and phospho-protein kinase B (pAkt) was determined by western blot analysis. miR-21 was transfected into MCF-7 cells and the anticancer effect of curcumin on cell viability and the expression of PTEN and pAkt was analyzed. The present results demonstrated that curcumin inhibited cell viability and induced cytotoxicity of MCF-7 cells in a concentration- and time-dependent manner, by inducing apoptosis and increasing caspase-3/9 activities. In addition, curcumin downregulated miR-21 expression in MCF-7 cells by upregulating the PTEN/Akt signaling pathway. The present study has for the first time, to the best of our knowledge, revealed the anticancer effect of curcumin in suppressing breast cancer
\end{abstract}

Correspondence to: Mr. Xinzheng Wang, Department III of General Surgery, The First Affiliated Hospital of Henan University of Science and Technology, 24 Jinghua Street, Jianxi, Luoyang, Henan 471000, P.R. China

E-mail: xinzhengwanghn@163.com

Key words: curcumin, breast cancer, miR-21, PTEN, Akt cell growth, and has elucidated that the miR-21/PTEN/Akt signaling pathway is a key mechanism for the anticancer effects of curcumin.

\section{Introduction}

Breast cancer is the most common malignant tumor among women and is a significant global health problem. It is estimated that $\sim 1.3$ million women are diagnosed with breast cancer and $>450,000$ breast cancer-associated mortalities are recorded every year (1). Although the morbidity of breast cancer and mortality rates have decreased, due to prevention, screening, early detection and treatment, and the survival time of breast cancer patients has been extended, there are a significant amount of individuals diagnosed with breast cancer, which transforms into malignant tumors $(2,3)$.

MicroRNAs (miRs) are a large family of single stranded non-coding RNAs composed of 22 nucleotides. miRs regulate gene expression, which affects various biological behaviors, including the formation, growth and development of embryos, hematopoiesis, proliferation, apoptosis and differentiation of cells, and occurrence and development of tumors (4). Increasing studies suggest that miRs are important in the occurrence and development of tumors, and certain miRs act as oncogenes or anti-oncogenes (5). One such miR is miR-21, which has been demonstrated to be overexpressed in pulmonary, mammary gland and prostate and colon malignant tumors, gastrointestinal, esophageal and pancreatic cancer and head and neck neoplasms (6).

Curcumin is a polyphenol with a low molecular weight and is extracted from Curcuma longa L, which belongs to the Zingiberaceae family (7). Generally, curcumin is regarded as the most effective constituent in turmeric and accounts for $2-8 \%$ in the majority of turmeric preparations. According to various studies, curcumin has numerous pharmacological effects, including anti-oxidative (8), anti-inflammatory (9), anticancer (10), free radical clearance (1) and antimicrobial effects (2). In addition, curcumin has numerous pharmacological functions on the cardiovascular and digestive systems (11). The present study investigated whether the anticancer effect of curcumin inhibits breast cancer cell growth through the miR-21/phosphatase and tensin homolog (PTEN)/protein kinase B (Akt) signaling pathway. 


\section{Materials and methods}

Materials. Dulbecco's modified Eagle's medium (DMEM) and fetal bovine serum (FBS) was obtained from HyClone ${ }^{\mathrm{TM}}$ (GE Healthcare, Logan, UT, USA). Curcumin (purity >98\%) was supplied by Sigma-Aldrich (St. Louis, MO, USA). 3-(4,5-dimethyl-2-thiazolyl)-2, 5-diphenyl-2H-tetrazolium bromide (MTT) and lactate dehydrogenase (LDH) were supplied by Tianjin Chemical Reagent No. 1 Plant (Tianjin, China). Annexin V-fluorescein isothiocyanate (FITC)/propidium iodide (PI) Apoptosis Detection kit was obtained from Beijing Biosea Biotechnology, Co., Ltd. (Beijing, China). A BCA Protein Assay kit was supplied by Wuhan Boster Bioengineering Co., Ltd. (Wuhan, China). Caspase-3 (C1116) and caspase-9 (C1158) activity kits were obtained from Beyotime Institute of Biotechnology (Beijing, China). TRIzol reagent was supplied by Invitrogen ${ }^{\mathrm{TM}}$ (Thermo Fisher Scientific, Inc., Waltham, MA, USA). Primescript ${ }^{\mathrm{TM}}$ RT Master mix kit was obtained from Takara Biotechnology Co., Ltd. (Dalian, China). ABI Prism 7900HT Real-Time PCR system was supplied by Applied Biosystems ${ }^{\circledR}$ (Thermo Fisher Scientific, Inc.).

Cell culture. Human breast cancer MCF-7 cell line was purchased from Shanghai Institute of Cell Biology, Chinese Academy of Sciences (Shanghai, China). The MCF-7 cells were cultured in DMEM containing 10\% FBS with $100 \mathrm{U} / \mathrm{ml}$ penicillin and $100 \mathrm{U} / \mathrm{ml}$ streptomycin (Sigma-Aldrich) in a humidified atmosphere of $95 \%$ air with $5 \% \mathrm{CO}_{2}$ at $37^{\circ} \mathrm{C}$.

MTT assay. MCF-7 cells were seeded at a density of $2 \times 10^{4}$ cells/well $(0.2 \mathrm{ml} /$ well) in 96 -well plates (Corning, Inc., Corning, NY, USA) for $24 \mathrm{~h}$. Following exposure to various concentrations of curcumin [0 (with DMSO vehicle), 0.5, 1.0, 2.0, 5.0 and $10.0 \mu \mathrm{M}$ ] for 24,48 and $72 \mathrm{~h}$, respectively (12), $20 \mu \mathrm{l}$ MTT solution (Tianjin Chemical Reagent No. 1 Plant, Tianjin, China) was added to each well and the cells were incubated for an additional $4 \mathrm{~h}$. In total, $200 \mu \mathrm{l}$ dimethyl sulfoxide (Sinopharm Chemical Reagent Co., Ltd., Shanghai, China) was added to each well and the plates were agitated for $20 \mathrm{~min}$ at room temperature. The absorbance of the samples was measured at $490 \mathrm{~nm}$ using a microplate reader (model 3550; Bio-Rad Laboratories, Inc., Hercules, CA, USA).

LDH assay. MCF-7 cells were seeded in 96-well plates at a density of $2 \times 10^{4}$ cells/well $(0.2 \mathrm{ml} /$ well $)$ for $24 \mathrm{~h}$. Following exposure to various concentrations of curcumin [0 (with DMSO vehicle), 0.5, 1.0, 2.0, 5.0 and $10.0 \mu \mathrm{M}$ ] for 24,48 and $72 \mathrm{~h}, 100 \mu \mathrm{l} \mathrm{LDH}$ solution was added to each well and the plates was incubated at room temperature for $30 \mathrm{~min}$. The absorbance of the samples was measured at $490 \mathrm{~nm}$ using a microplate reader (Bio-Rad Laboratories, Inc.).

Cell apoptosis evaluation using flow cytometry. MCF-7 cells were seeded in 6-well plates (Corning, Inc.) at a density of $1 \times 10^{6}$ cells/well $(2 \mathrm{ml} /$ well) for $24 \mathrm{~h}$. The cells were centrifuged at 2,000 $\mathrm{x} g$ for $10 \mathrm{~min}$ and collected following treatment with curcumin at 0 (with DMSO vehicle), 1, 2 and $5 \mu \mathrm{M}$ for $48 \mathrm{~h}$. The cells were then washed twice with cold phosphate-buffered saline (PBS). The MCF-7 cells were resuspended with $500 \mu \mathrm{l}$ binding buffer (Beijing Biosea Biotechnology, Co., Ltd.,
Beijing, China). Subsequently, miscible liquids were mixed with $10 \mu \mathrm{l}$ Annexin $\mathrm{V}$ for $30 \mathrm{~min}$ in the dark at room temperature, followed by the addition of $5 \mu$ l PI (Beijing Biosea Biotechnology, Co., Ltd.) for $30 \mathrm{~min}$ in the dark at room temperature. Subsequently, the samples were analyzed by FACSAria flow cytometer (BD Biosciences, Franklin Lakes, NJ, USA).

4',6-diamidino-2-phenylindole (DAPI) staining assay. MCF-7 cells were seeded in 6-well plates at a density of $1 \times 10^{6}$ cells/well $(2 \mathrm{ml} /$ well $)$ for $24 \mathrm{~h}$. The cells were collected following treatment with curcumin at 0 (with DMSO vehicle), 1,2 and $5 \mu \mathrm{M}$ for $48 \mathrm{~h}$, and subsequently washed twice with cold PBS. The MCF-7 cells were fixed in 4\% paraformaldehyde (Sinopharm Chemical Reagent Co., Ltd.), permeabilized with $0.1 \%$ Triton X-100 (Sinopharm Chemical Reagent Co., Ltd.) and stained with $2 \mu \mathrm{g} / \mathrm{ml}$ DAPI (Beyotime Institute of Biotechnology) for $10 \mathrm{~min}$. Nucleic morphology of the MCF-7 cells was observed under a fluorescence microscope (Nikon Corporation, Tokyo, Japan).

Caspase- 3 and caspase-9 activities. MCF-7 cells were seeded in 6 -well plates at a density of $1 \times 10^{6}$ cells/well $(2 \mathrm{ml} /$ well) for $24 \mathrm{~h}$. MCF-7 cells were collected following treatment with curcumin at 0 (with DMSO vehicle), 1,2 and $5 \mu \mathrm{M}$ for $48 \mathrm{~h}$, and the cells were subjected to lysis by a cell lysis buffer (Beyotime Institute of Biotechnology) for $0.5-1 \mathrm{~h}$ on ice. The cell lysates were centrifuged at $12,000 \mathrm{xg}$ for $10 \mathrm{~min}$ at $4^{\circ} \mathrm{C}$. The concentration of the proteins was determined by BCA Protein Assay kit. The proteins were mixed with reaction buffers from the caspase-3/9 activity kits (caspase-3, Ac-DEVD-pNA; caspase-9, Ac-LEHD-pNA) and incubated at $37^{\circ} \mathrm{C}$ for $2 \mathrm{~h}$ in the dark. The activities of caspase-3 and caspase- 9 were measured at an absorbance of $405 \mathrm{~nm}$ using the microplate reader from Bio-Rad Laboratories, Inc.

Reverse transcription-quantitative polymerase chain reaction $(q P C R)$ of miR-21 expression. MCF-7 cells were seeded in 6 -well plates at a density of $1 \times 10^{6}$ cells/well $(2 \mathrm{ml} /$ well) for $24 \mathrm{~h}$. MCF-7 cells were collected following treatment with curcumin at 0 (with DMSO vehicle), 1,2 and $5 \mu \mathrm{M}$ for $48 \mathrm{~h}$, and total RNA was extracted using TRIzol reagent (Invitrogen ${ }^{\mathrm{TM}}$; Thermo Fisher Scientific, Inc.), according to the manufacturer's protocol. PrimeScript ${ }^{\mathrm{TM}}$ RT Master mix was used to transcribe cDNA according to the manufacturer's protocol (Takara Biotechnology Co., Ltd.). qPCR was performed with an ABI Prism 7900HT Real-Time PCR system and the SYBR Green I florescent dye method (Applied Biosystems; Thermo Fisher Scientific, Inc.) was used to quantify miR-21 expression (3). PCR was initiated at $95^{\circ} \mathrm{C}$ for $3 \mathrm{~min}$, followed by 40 cycles at $95^{\circ} \mathrm{C}$ for $20 \mathrm{sec}$ and $60^{\circ} \mathrm{C}$ for $30 \mathrm{sec}$. The primers used are as follows: miR-21, forward 5'-GGGGTAGCTTATCAGACTGATG-3' and reverse 5'-TGTCGTGGAGCGGCAATTG-3'; U6, forward 5'-CGCTTC GGCACATATACTA-3' and reverse 5'-CGCTTCACGAAT TTGCGTGTCA-3'. The relative level of miR-21 was calculated with the comparative $2^{-\Delta \Delta \mathrm{Cq}}$ method using small RNA U6 (13).

Western blot analysis for PTEN/Akt protein expression. MCF-7 cells were seeded in 6-well plates at a density of $1 \times 10^{6}$ cells/well $(2 \mathrm{ml} /$ well $)$ for $24 \mathrm{~h}$. The cells were collected following treatment with curcumin at 0 (with DMSO vehicle), 1,2 and $5 \mu \mathrm{M}$ for $48 \mathrm{~h}$, and MCF-7 cells were subjected to 
cell lysis with a cell lysis buffer for $30 \mathrm{~min}$ to $1 \mathrm{~h}$ on ice. The cell lysates were centrifuged at $12,000 \mathrm{x}$ g for $10 \mathrm{~min}$ at $4^{\circ} \mathrm{C}$ and the concentration of proteins was determined by BCA Protein Assay kit. The proteins were subjected to 12\% sodium dodecyl sulfate-polyacrylamide gel electrophoresis. Following electrophoresis, the gels were transferred to polyvinylidene difluoride membrane $(0.22 \mathrm{~mm})$. The membrane was blocked in 5\% non-fat milk in PBS at room temperature for $2 \mathrm{~h}$. The transferred membrane was incubated with rabbit polyclonal anti-PTEN (dilution, 1:1,500; sc-6817-R; Santa Cruz Biotechnologies, Inc., Dallas, TX, USA), anti-phospho-Akt (p-Akt; dilution, 1:1,500; sc-135650; Santa Cruz Biotechnologies, Inc.) and anti- $\beta$-actin (dilution, 1:500; D110007; Sangon Biotech, Co., Ltd., Shanghai, China) antibodies overnight at $4^{\circ} \mathrm{C}$. After washing with PBS three times, the membrane was incubated with a secondary polyclonal peroxidase-labeled antibody (6403-05; Wuhan Amyjet Scientific, Inc., Wuhan, China) for $2 \mathrm{~h}$. The membrane was detected using the Immun-Star ${ }^{\mathrm{TM}}$ WesternC ${ }^{\text {TM }}$ Chemiluminescent kit (Bio-Rad Laboratories, Inc.) and autoradiography films (Amersham HyperFilm ECL; GE Healthcare). Quantification was performed using Quantity One software version 3.0 (Bio-Rad Laboratories, Inc.).

Transfection of MCF-7 cells with miR-21 plasmids. Negative control plasmids and miR-21 plasmids were designed and purchased from Sangon Biotech, Co., Ltd. The MCF-7 cells were seeded onto a 6-well plate at a density of $1 \times 10^{6}$ cells/well for $24 \mathrm{~h}$, and were transiently transfected using Lipofectamine ${ }^{\circledR} 2000$ transfection reagent (Invitrogen ${ }^{\mathrm{TM}}$; Thermo Fisher Scientific, Inc.), according to the manufacturer's protocol.

Statistical analysis. Data are expressed as the mean \pm standard error of the mean. Comparisons of two groups were performed using Student's t-test and multiple comparisons were made by performing one-way analysis of variance followed by Bonferroni's test. Statistical analysis was conducted using SPSS software (version 15; SPSS, Inc., Chicago, IL, USA). P $<0.05$ was considered to indicate a statistically significant difference.

\section{Results}

Anticancer effect of curcumin inhibits cell growth. The structure of curcumin is shown in Fig. 1. MTT assay revealed that the growth of MCF-7 cells was reduced following treatment with various concentrations of curcumin $(0,0.5,1.0,2.0$, 5.0 and $10.0 \mu \mathrm{M}$ ) for 24,48 and $72 \mathrm{~h}$. Subsequent to treatment with 2,5 and $10 \mu \mathrm{M}$ curcumin for $48(\mathrm{P}=0.0097,0.0041$ and 0.0022 , respectively) or $72 \mathrm{~h}(\mathrm{P}=0.0072,0.0033$ and 0.0009 , respectively), the cell growth of MCF-7 cells was significantly inhibited in a concentration- and time-dependent manner compared with cells treated with $0 \mu \mathrm{M}$ curcumin (Fig. 2).

Anticancer effect of curcumin induces cytotoxicity. The effects of treating MCF-7 cells with various concentrations of curcumin $(0,0.5,1.0,2.0,5.0$ and $10.0 \mu \mathrm{M})$ for 24,48 and $72 \mathrm{~h}$ on cell cytotoxicity was analyzed using a LDH assay. Curcumin treatment at 2, 5 and $10 \mu \mathrm{M}$ for $48(\mathrm{P}=0.0088,0.0038$ and 0.0017 , respectively) and $72 \mathrm{~h}(\mathrm{P}=0.0079,0.0027$ and 0.0003 , respectively) increased the cytotoxicity of MCF-7 cells in a concentration- and time-dependent manner (Fig. 3).<smiles>COc1cc(/C=C/C(=O)CC(=O)/C=C/c2ccc(O)c(OC)c2)ccc1O</smiles>

Figure 1. Chemical structure of curcumin.

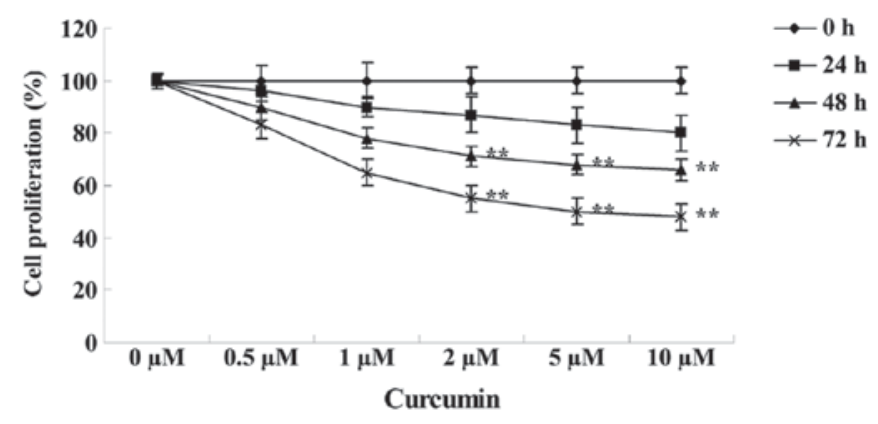

Figure 2. Anticancer effect of curcumin inhibits human breast cancer MCF-7 cell proliferation. Data are presented as the mean \pm standard error of the mean. ${ }^{* *} \mathrm{P}<0.01$ vs. $0 \mu \mathrm{M}$ curcumin-treatment group.

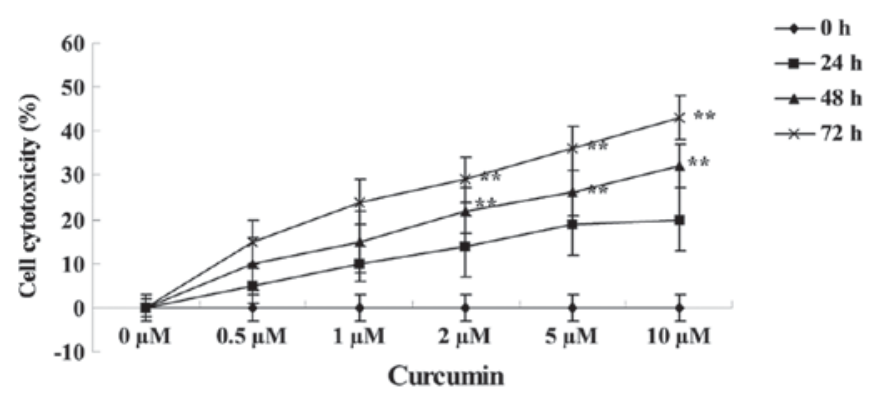

Figure 3. Anticancer effect of curcumin induces cytotoxicity in human breast cancer MCF-7 cells. Data are presented as the mean \pm standard error of the mean. ${ }^{* *} \mathrm{P}<0.01$ vs. $0 \mu \mathrm{M}$ curcumin-treatment group.

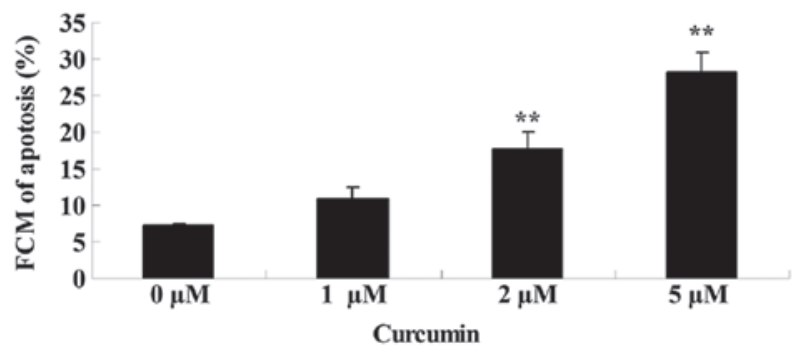

Figures 4. Anticancer effect of curcumin induces apoptosis of human breast cancer MCF-7 cells. Data are presented as the mean \pm standard error of the mean. ${ }^{* *} \mathrm{P}<0.01$ vs. $0 \mu \mathrm{M}$ curcumin-treatment group. FCM, flow cytometry.

Anticancer effect of curcumin induces cell apoptosis. The effects of treating MCF-7 cells with various concentrations of curcumin $(0,1,2$ and $5 \mu \mathrm{M})$ for $48 \mathrm{~h}$ on cell apoptosis was analyzed using flow cytometry. As shown in Fig. 4, curcumin induced significant apoptotic cell death of MCF-7 cells in a concentration-dependent manner, when treated with 2 $(\mathrm{P}=0.0021)$ and $5 \mu \mathrm{M}(\mathrm{P}=0.0004)$ at $48 \mathrm{~h}$. 


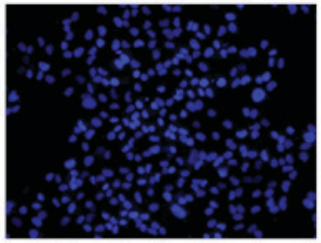

$0 \mu \mathrm{M}$ Curcumin

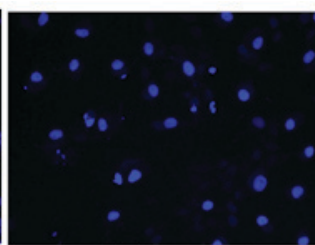

$1 \mu \mathrm{M}$ Curcumin

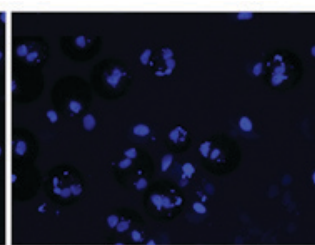

$2 \mu \mathrm{M}$ Curcumin

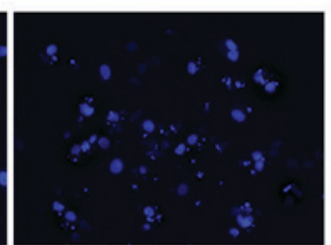

$5 \mu \mathrm{M}$ Curcumin

Figure 5. Anticancer effect of curcumin induces apoptotic nucleic morphology in human breast cancer MCF-7 cells stained with 4',6-diamidino-2-phenylindole.
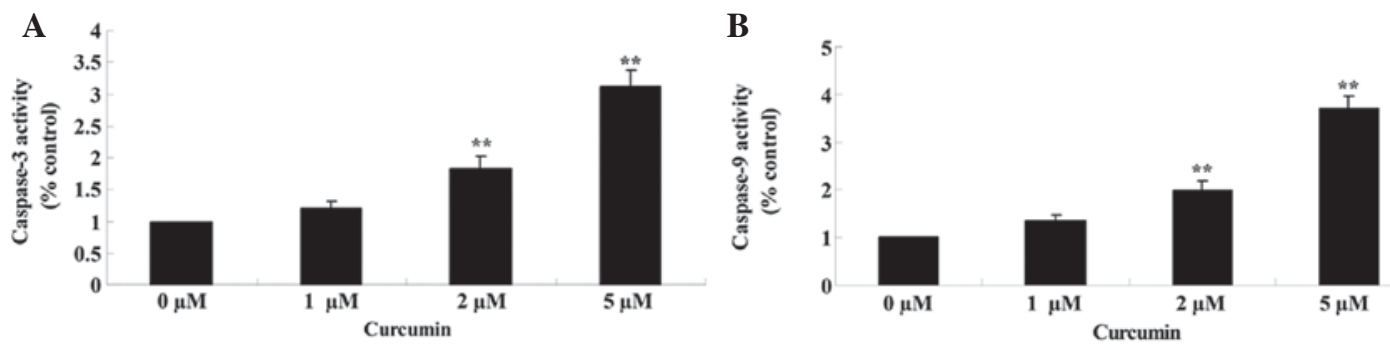

Figure 6. Anticancer effect of curcumin induces (A) caspase-3 and (B) caspase-9 activities in human breast cancer MCF-7 cells. Data are presented as the mean \pm standard error of the mean. ${ }^{* *} \mathrm{P}<0.01$ vs. $0 \mu \mathrm{M}$ curcumin-treatment group.

Anticancer effect of curcumin induces apoptotic morphology in cells. The effects of treating MCF-7 cells with various concentrations of curcumin $(0,1,2$ and $5 \mu \mathrm{M})$ for $48 \mathrm{~h}$ on nucleic morphology was analyzed using DAPI staining. As shown in Fig. 5, nucleic apoptosis of MCF-7 cells was observed to be significantly promoted by treatment with 2 and $5 \mu \mathrm{M}$ curcumin at $48 \mathrm{~h}$ in a concentration-dependent manner.

Anticancer effect of curcumin induces caspase-3/9 activities. Effects of curcumin on caspase-3/9 activities of MCF-7 cells was examined using commercial caspase-3/9 activity kits, after the cells had been treated with curcumin at $0,1,2$ and $5 \mu \mathrm{M}$ for $48 \mathrm{~h}$. When treated with curcumin at 2 and $5 \mu \mathrm{M}$, caspase-3 $(\mathrm{P}=0.0057$ and 0.0012$)$ and $-9(\mathrm{P}=0.0042$ and 0.0008 ) activities in MCF-7 cells were significantly increased in a concentration-dependent manner (Fig. 6A and B).

Anticancer effect of curcumin regulates miR-21 expression. The effects of treating MCF-7 cells with various concentrations of curcumin $(0,1,2$ and $5 \mu \mathrm{M})$ for $48 \mathrm{~h}$ on the expression of miR-21 was analyzed using qPCR. Fig. 7 reveals that the expression of miR-21 was significantly suppressed in cells treated with curcumin in a concentration-dependent manner $(\mathrm{P}=0.0079$ and 0.0021$)$.

Anticancer effect of curcumin regulates PTEN/Akt. Effects of curcumin on the PTEN/Akt signaling pathway in MCF-7 cells was verified by western blot analysis, subsequent to the cells being treated with curcumin at $0,1,2$ and $5 \mu \mathrm{M}$ for $48 \mathrm{~h}$. Following treatment, PTEN protein expression was significantly increased $(\mathrm{P}=0.0081$ and 0.0009$)$ and $\mathrm{p}$-Akt protein expression was significantly decreased $(\mathrm{P}=0.0092$ and 0.0033$)$ in a concentration-dependent manner (Fig. 8).

Upregulation of miR-21 regulates the anticancer effect of curcumin on cell growth. The previous results had demonstrated that miR-21 plays a role in the anticancer effect of curcumin on

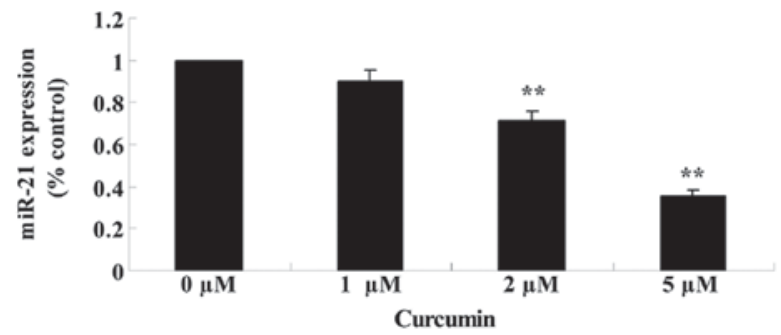

Figure 7. Anticancer effect of curcumin decreases miR-21 expression in human breast cancer MCF-7 cells. Data are presented as the mean \pm standard error of the mean. ${ }^{* *} \mathrm{P}<0.01$ vs. $0 \mu \mathrm{M}$ curcumin-treatment group. miR, microRNA.

cell growth. Therefore, miR-21 was upregulated in MCF-7 cells by transfection of MCF-7 cells with miR-21 plasmids, and the anticancer effect of curcumin on the cell growth of these transfected cells was evaluated. miR-21 plasmids significantly upregulated miR-21 expression (Fig. 9A). Overexpression of miR-21 significantly reduced the anticancer effect of curcumin, as demonstrated by an increase in cell proliferation of transfected cells compared with parental MCF-7 cells ( $\mathrm{P}=0.0037$; Fig. 9B).

Upregulation of miR-21 regulates the anticancer effect of curcumin through the PTEN/Akt pathway. The present study additionally investigated whether miR-21 regulates the anticancer effect of curcumin through the PTEN/Akt pathway in MCF-7 cells. As shown in Fig. 10, miR-21 plasmids significantly decreased the anticancer effect of curcumin by decreasing the expression of PTEN and increasing the expression of $\mathrm{p}-\mathrm{Akt}(\mathrm{P}=0.0039)$.

\section{Discussion}

Breast cancer is one of the most common malignant tumors worldwide. According to the latest global estimates, in 2002 morbidity from breast cancer was 37.5 per 100,000 individuals, 
A

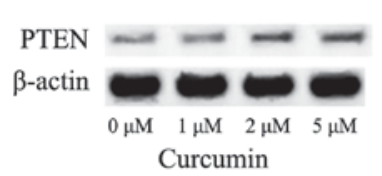

C

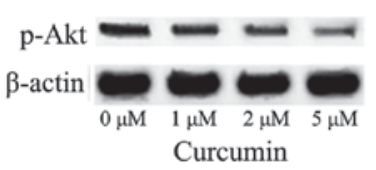

B

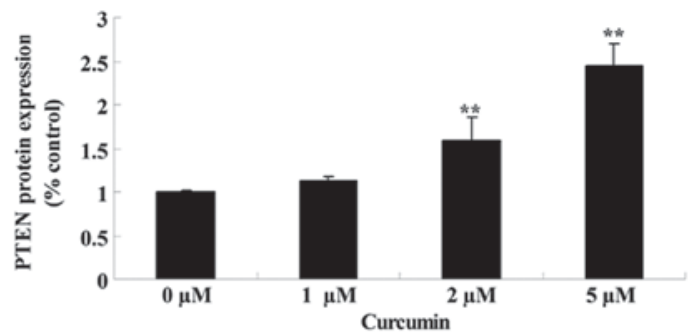

D

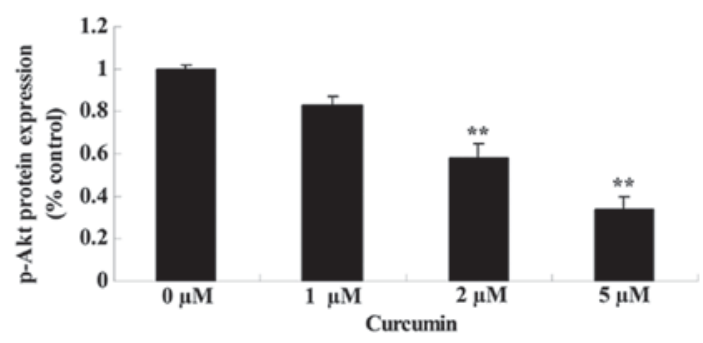

Figure 8. Anticancer effect of curcumin regulates PTEN/Akt protein expression in human breast cancer MCF-7 cells. Protein expression of (A and B) PTEN and $(\mathrm{C}$ and $\mathrm{D}) \mathrm{p}$-Akt was upregulated and downregulated by curcumin, respectively, in a concentration-dependent manner. Data are presented as the mean \pm standard error of the mean. ${ }^{* *} \mathrm{P}<0.01$ vs. $0 \mu \mathrm{M}$ curcumin-treatment group. PTEN, phosphatase and tensin homolog; p-Akt, phospho-protein kinase B.
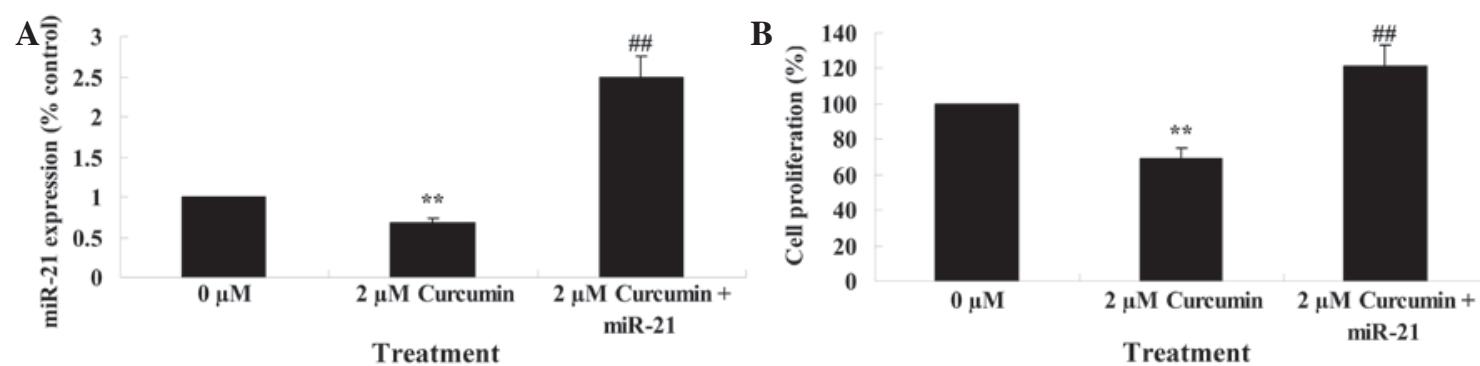

Figure 9. Upregulation of miR-21 decreases the anticancer effect of curcumin on human breast cancer MCF-7 cell growth. (A) MCF-7 cells transfected with miR-21 plasmids and treated with curcumin upregulate miR-21 expression. (B) MCF-7 cells transfected with miR-21 plasmids decrease the anticancer activity of curcumin. ${ }^{* *} \mathrm{P}<0.01$ vs. $0 \mu \mathrm{M}$ curcumin-treatment group; ${ }^{\# \#} \mathrm{P}<0.01$ vs. $2 \mu \mathrm{M}$ curcumin-treatment group. miR, microRNA.

A

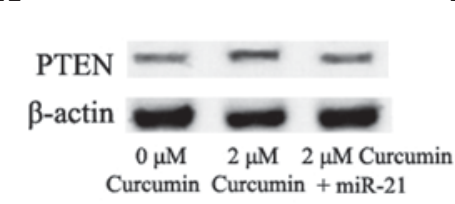

C

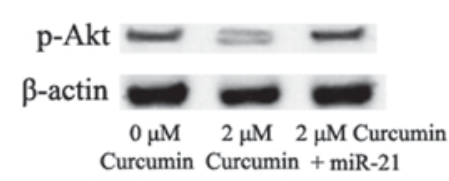

B

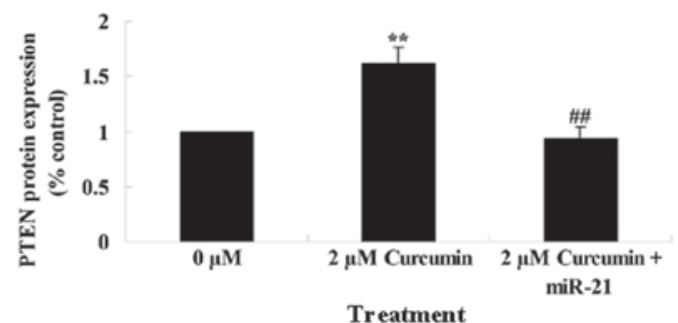

D

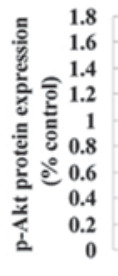

Treatment

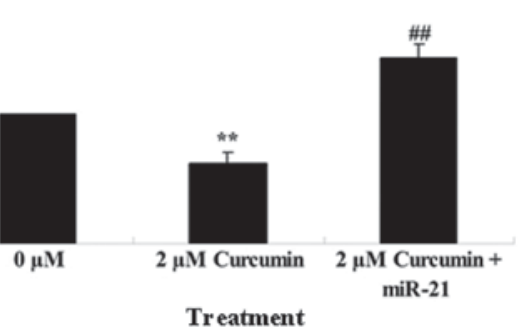

Figure 10. Upregulation of miR-21 regulates the anticancer effect of curcumin on the PTEN/Akt pathway in human breast cancer MCF-7 cells. MCF-7 cells transfected with miR-21 plasmids (A and B) decreased the protein expression of PTEN and (C and D) increased the protein expression of p-Akt. Data are presented as the mean \pm standard error of the mean. ${ }^{* *} \mathrm{P}<0.01$ vs. $0 \mu \mathrm{M}$ curcumin-treatment group; ${ }^{\# /} \mathrm{P}<0.01 \mathrm{vs} .2 \mu \mathrm{M}$ curcumin-treatment group. miR, microRNA; PTEN, phosphatase and tensin homolog; p-Akt, phospho-protein kinase B.

and the incidence was 1.15 million patients (3). For nearly 30 years, the morbidity caused by breast cancer in the majority of countries has increased $(14,15)$. The present study demonstrates that the anticancer effect of curcumin 
significantly inhibits cell growth, increases cytotoxicity and induces apoptosis and caspase-3/9 activities in MCF-7 cells in a concentration- and time-dependent manner. In addition, the anticancer activity of curcumin has been demonstrated to inhibit cell proliferation and induce apoptosis in lung adenocarcinoma A549 cells (16) non-small cell lung cancer (17), gastric cancer (12) and colorectal cancer (18). Therefore, curcumin may be a potential drug for breast cancer treatment.

For numerous types of tumors, inhibiting the expression of miR-21 leads to an inhibition in cell growth, induces apoptosis and inhibits cell migration and invasion (19). miR-21 is regarded as a proto-oncogene, and has an increased expression in various human cancer tissues and cells, including glioma, multiple myeloma and cervical, ovarian, bladder, prostate, lung and breast cancer $(20,21)$. miR-21 not only participates in the differentiation, proliferation and apoptosis of cells, but is closely associated with the occurrence, growth, invasion and metastasis of tumors (22). The present study demonstrates that the anticancer effect of curcumin significantly reduced the expression of miR-21 in MCF-7 cells in a concentration-dependent manner. Similarly, Mudduluru et al (23) revealed that curcumin inhibits the invasion and metastasis of colorectal cancer cells through the regulation of miR-21 expression. Gaining insight into the molecular characteristics of miR-21 may aid in understanding the antitumor function of curcumin in various human cancers.

Previous studies have suggested that PTEN is a target gene with certain biological functions. As a tumor-inhibiting factor, PTEN controls the growth, invasion and metastasis of tumors (24). Inhibition of PTEN may affect downstream molecules of the phosphoinositide 3-kinase (PI3K) signaling pathway, including Akt, which leads to a stimulation of the growth and invasion and metastatic abilities of tumors (25). An overexpression of miR-21 in human hepatoma cells leads to a decrease in the expression of PTEN; therefore, it may be hypothesized that there is a negative association between PTEN and miR-21 (26). In addition, miR-21 possibly promotes the occurrence and growth of tumors by inhibiting the expressions of PTEN (27). The present study demonstrated that the anticancer effects of curcumin significantly promoted the protein expression of PTEN and suppressed the protein expression of p-Akt in MCF-7 cells. Furthermore, Khaw et al (28) reported that curcumin inhibits telomerase and induces cell apoptosis of brain tumour cells by upregulating the expression of PTEN. Additionally, Wong et al (29) revealed that curcumin inhibits uterine leiomyosarcoma cells via Akt. However, the detailed mechanisms concerning the effects of curcumin treatment on the PTEN/Akt pathway remains unclear, and further clarification is required.

The PTEN/PI3K/Akt signaling pathway exists extensively in all types of tumor cells (30). Akt affects the apoptosis of cancer cells, myocardial cells and other cells (31). This pathway affects cell cycle progress by controlling the activation of genes associated with apoptosis; therefore, control of the growth and proliferation of cells is via this pathway. This pathway participates in the formation of tumor vasculature and consequently is important in the formation of tumors (32). In addition, the PTEN/PI3K/Akt pathway participates in the invasion and metastasis of tumors. PTEN inhibits the formation of tumors through negative regulation of the PI3K/Akt signaling pathway, and an inactivation or mutation of PTEN genes decreases the inhibition of the pathway causing cell canceration (33). In the process of PI3K/AKT signal transduction, PI3K is activated, which in turn activates PIP3 as a secondary messenger that activates signal molecules downstream. The PI3K signaling pathway is important in a series of pathophysiological procedures, including cell differentiation, apoptosis, proliferation and migration and the neoplastic transformation of cells (34). Certain studies have demonstrated that PTEN/PI3K/Akt signaling pathways are closely associated with the cell growth, proliferation, survival and apoptosis, metabolism of tumors, tumor angiogenesis, invasion and metastasis, drug resistance in cancer and tumor immune response escape (35).

Overall, an upregulation of miR-21 significantly inhibited the anticancer effect of curcumin on cell growth in MCF-7 cells, suppressed the promotion of PTEN protein expression and increased p-Akt protein expression. In conclusion, the present results of this initial study indicate that curcumin reduces the malignancy of breast cancer cells, and this anticancer effect is controlled by the miR-21/PTEN/Akt signaling pathway. These results provide a basis for the future management of breast cancer. In conclusion, the results of the present study indicate that curcumin reduces the malignancy of breast cancer cells, and this anticancer effect is controlled by a miR-21/PTEN/ Akt signaling pathway, which may present a novel method of treating breast cancer.

\section{References}

1. Pu Z, Yuan X, Zhang X, Chen Q and Xie H: Meta-analysis on the association between CYP2D6*10 gene polymorphism and disease free survival of breast cancer patients receiving tamoxifen treatment in Asia. Bangladesh J Pharmacol 9: 652-662, 2014.

2. Rao X, Evans J, Chae H, Pilrose J, Kim S, Yan P, Huang RL, Lai HC, Lin H, Liu Y, et al: CpG island shore methylation regulates caveolin-1 expression in breast cancer. Oncogene 32: 4519-4528, 2013

3. Zhang J, Wang Y, Yin Q, Zhang W, Zhang T and Niu Y: An associated classification of triple negative breast cancer: The risk of relapse and the response to chemotherapy. Int J Clin Exp Pathol 6: 1380-1391, 2013.

4. Moshammer MI, Kalipciyan M, Bartsch R, Steger GG, Sedivy R and Mader RM: Exosomal microRNA transfer varies with specific microRNAs functional in colorectal cancer and cellular differentiation. Int J Clin Pharmacol Ther 52: 87-88, 2014.

5. Catania A, Maira F, Skarmoutsou E, D'Amico F, Abounader R and Mazzarino MC: Insight into the role of microRNAs in brain tumors (review). Int J Oncol 40: 605-624, 2012.

6. Osawa S, Shimada Y, Sekine S, Okumura T, Nagata T, Fukuoka J and Tsukada K: MicroRNA profiling of gastric cancer patients from formalin-fixed paraffin-embedded samples. Oncol Lett 2: 613-619, 2011.

7. Chiu J, Khan ZA, Farhangkhoee $\mathrm{H}$ and Chakrabarti S: Curcumin prevents diabetes-associated abnormalities in the kidneys by inhibiting p300 and nuclear factor-kappaB. Nutrition 25: 964-972, 2009

8. Wang J, Du XX, Jiang H and Xie JX: Curcumin attenuates 6-hydroxydopamine-induced cytotoxicity by anti-oxidation and nuclear factor-kappa B modulation in MES23.5 cells. Biochem Pharmacol 78: 178-183, 2009.

9. Wu SJ, Tam KW, Tsai YH, Chang CC and Chao JC: Curcumin and saikosaponin a inhibit chemical-induced liver inflammation and fibrosis in rats. Am J Chin Med 38: 99-111, 2010.

10. Zhen L, Fan D, Yi X, Cao X, Chen D and Wang L: Curcumin inhibits oral squamous cell carcinoma proliferation and invasion via EGFR signaling pathways. Int J Clin Exp Pathol 7: 6438-6446, 2014. 
11. Ye M, Zhang J, Zhang J, Miao Q, Yao L and Zhang J: Curcumin promotes apoptosis by activating the p53-miR-192-5p/215-XIAP pathway in non-small cell lung cancer. Cancer Lett 357: 196-205, 2015.

12. Liu X, Sun K, Song A, Zhang X, Zhang X and He X: Curcumin inhibits proliferation of gastric cancer cells by impairing ATP-sensitive potassium channel opening. World J Surg Oncol 12: 389, 2014

13. Livak and Schmittgen: Analysis of relative gene expression data using real-time quantitative PCR and the $2-\Delta \Delta \mathrm{Ct}$ method. Methods 25: 402-408, 2001.

14. Jiang H, Bai X, Zhang C and Zhang X: Evaluation of HER2 gene amplification in breast cancer using nuclei microarray in situ hybridization. Int J Mol Sci 13: 5519-5527, 2012.

15. Menendez JA and Lupu R: RNA interference-mediated silencing of the p53 tumor-suppressor protein drastically increases apoptosis after inhibition of endogenous fatty acid metabolism in breast cancer cells. Int J Mol Med 15: 33-40, 2005.

16. Teong B, Lin CY, Chang SJ, Niu GC, Yao CH, Chen IF and Kuo SM: Enhanced anti-cancer activity by curcumin-loaded hydrogel nanoparticle derived aggregates on A549 lung adenocarcinoma cells. J Mater Sci Mater Med 26: 5357, 2015.

17. Chen QY, Jiao DM, Wang LF, Wang L, Hu HZ, Song J, Yan J, Wu LJ and Shi JG: Curcumin inhibits proliferation-migration of NSCLC by steering crosstalk between a Wnt signaling pathway and an adherens junction via EGR-1. Mol Biosyst 11: 859-868, 2015.

18. Fan L, Li A, Li W, Cai P, Yang B, Zhang M, Gu Y, Shu Y, Sun Y, Shen Y, et al: Novel role of Sarco/endoplasmic reticulum calcium ATPase 2 in development of colorectal cancer and its regulation by F36, a curcumin analog. Biomed Pharmacother 68: 1141-1148, 2014.

19. Shi J: Considering exosomal miR-21 as a biomarker for cancer. J Clin Med 5: 42, 2016

20. Frey MR, Carraro G, Batra RK, Polk DB and Warburton D: Sprouty keeps bowel kinases regular in colon cancer, while miR-21 targets Sprouty. Cancer Biol Ther 11: 122-124, 2011.

21. Han M, Liu M, Wang Y, Chen X, Xu J, Sun Y, Zhao L, Qu H, Fan Y and WuC: Antagonism of miR-21 reverses epithelial-mesenchymal transition and cancer stem cell phenotype through AKT/ERK1/2 inactivation by targeting PTEN. PLoS One 7: e39520, 2012

22. Yin C, Zhou X, Dang Y, Yan J and Zhang G: Potential role of circulating miR-21 in the diagnosis and prognosis of digestive System Cancer: A systematic review and meta-analysis. Medicine (Baltimore) 94: e2123, 2015.

23. Mudduluru G, George-William JN, Muppala S, Asangani IA, Kumarswamy R, Nelson LD and Allgayer H: Curcumin regulates miR-21 expression and inhibits invasion and metastasis in colorectal cancer. Biosci Rep 31: 185-197, 2011.
24. Leslie NR, Kriplani N, Hermida MA, Alvarez-Garcia V and Wise HM: The PTEN protein: Cellular localization and post-translational regulation. Biochem Soc Trans 44: 273-278, 2016.

25. Yi XP, Han T, Li YX, Long XY and Li WZ: Simultaneous silencing of XIAP and survivin causes partial mesenchymal-epithelial transition of human pancreatic cancer cells via the PTEN/PI3K/Akt pathway. Mol Med Rep 12: 601-608, 2015

26. He C, Dong X, Zhai B, Jiang X, Dong D, Li B, Jiang H, Xu S and Sun X: MiR-21 mediates sorafenib resistance of hepatocellular carcinoma cells by inhibiting autophagy via the PTEN/Akt pathway. Oncotarget 6: 28867-28881, 2015

27. Schwarzenbach H, Milde-Langosch K, Steinbach B, Müller V and Pantel K: Diagnostic potential of PTEN-targeting miR-214 in the blood of breast cancer patients. Breast Cancer Res Treat 134: 933-941, 2012.

28. Khaw AK, Hande MP, Kalthur G and Hande MP: Curcumin inhibits telomerase and induces telomere shortening and apoptosis in brain tumour cells. J Cell Biochem 114: 1257-1270, 2013.

29. Wong TF, Takeda T, Li B, Tsuiji K, Kitamura M, Kondo A and Yaegashi N: Curcumin disrupts uterine leiomyosarcoma cells through AKT-mTOR pathway inhibition. Gynecol Oncol 122: $141-148,2011$.

30. Zhang J, Yang Y, Zhang Z, He Y, Liu Z, Yu Y, Wu S, Cai B and Feng Y: Gankyrin plays an essential role in estrogen-driven and GPR30-mediated endometrial carcinoma cell proliferation via the PTEN/PI3K/AKT signaling pathway. Cancer Lett 339: 279-287, 2013

31. Xue G, Zippelius A, Wicki A, Mandalà M, Tang F, Massi D and Hemmings BA: Integrated Akt/PKB signaling in immunomodulation and its potential role in cancer immunotherapy. J Natl Cancer Inst 107: 2015.

32. Park JH, Lee JY, Shin DH, Jang KS, Kim HJ and Kong G: Loss of Mel-18 induces tumor angiogenesis through enhancing the activity and expression of HIF-1alpha mediated by the PTEN/PI3K/Akt pathway. Oncogene 30: 4578-4589, 2011.

33. Zhao M, Zhou A, Xu L and Zhang X: The role of TLR4-mediated $\mathrm{PTEN} / \mathrm{PI} 3 \mathrm{~K} / \mathrm{AKT} / \mathrm{NF}-\kappa \mathrm{B}$ signaling pathway in neuroinflammation in hippocampal neurons. Neuroscience 269: 93-101, 2014.

34. Li P, Xiao LY and Tan H: Muc-1 promotes migration and invasion of oral squamous cell carcinoma cells via PI3K-Akt signaling. Int J Clin Exp Pathol 8: 10365-10374, 2015

35. Yang X, Cheng Y, Li P, Tao J, Deng X, Zhang X, Gu M, Lu Q and Yin C: A lentiviral sponge for miRNA-21 diminishes aerobic glycolysis in bladder cancer T24 cells via the PTEN/PI3K/AKT/mTOR axis. Tumour Biol 36: 383-391, 2015. 